\title{
Physics in Elementary School
}

Atoms and nuclei were easy. Quarks and leptons were easy. Temperature and pressure were easy. But centripetal acceleration? How do you get that across when you don't want to muddle elementary school students' heads with all that boring $\mathbf{F}=m \mathbf{a}$ stuff? It was the opening of the fourth session. Suddenly it hit me! I had them form a circle and hold hands. One by one, each kid ran around in a circle inside the large circle of kids. Faster and faster, I demanded! One by one they whispered to me that they had to push in toward the center to keep going in a circle. Wow, if only the college kids would be willing to do this. (Actually they had to push out. The floor had to push in. But who cares?)

For me, it had begun at an open house. The instigator was Marlene Davis, my son's highly innovative grade-two teacher at the Merion Elementary School. 'You're a physicist! Won't you come in and teach some physics?" she said. "What!" I said. "I teach undergraduate college-level physics and graduate-level quantum mechanics and solid-state physics. What could I possibly do? I don't know how to teach little kids." Well, it didn't take much convincing. A chance to do real physics with sevenyear-olds who hadn't yet been systematically taught to hate science. Being a showman at heart I couldn't resist. Since then, I have done kindergarten, grade three, and grade four. So let me tell you briefly how you, as a complete novice, can have great fun in your own local elementary school, and do a great public service at the same time.

First of all, having come in through the old system, I know nothing of teaching theory. What level is appropriate? Well, I realized that in teaching physics responsibly there is only one level. When a physicist talks about "level," she means "mathematcal content." So that was simple: none! What subjects? This is important: It doesn't matter. Start with whatever you are comfortable with and let the children take you in absolutely any direction whatsover. In one session, I planned to talk about the relationship between temperature and pressure and the molecular makeup of matter. Somehow the molecules became smoke and suddenly we were talking about how light goes (or doesn't go) through things. (Fortunately, I just happened to have a laser in my suitcase and lots of liquid nitrogen, which makes great "smoke.") Don't be rigid. Be willing to change subjects at the drop of a hat. If we taught the regular high school and introductory college classes like this, I think we would still get everything done. After each lecture one ticks off the topics covered. Why shouldn't it be all over the map? At a more advanced level, wrap-up and summary sessions can be introduced as appropriate.

I discovered three cardinal rules. The first rule is that you have to know what you are talking about very, very well. I couldn't have done this for the first five years or so of teaching university physics. In some sense, I prepared for thousands of hours for this task by teaching regular introductory calculus-based physics courses and "physics for poets" courses, as well as advanced undergraduate courses. In the grade-two class, I occasionally had wandering quarks of several colors and flavors (i.e., seven-year-olds with various identifying features), exchanging gluons (pieces of colored paper), and playing by the rules to form mesons and hadrons. Although I think we got the basics, I could have done a better job if I had understood the physics better. (I am a common garden-variety solid-state experimentalist.)

The second rule is that either the children have to be involved in the action in a big way or you have to have ritzy, attentiongetting demonstrations. Bring lots of stuff. It helps if you work at an institution with considerable resources, since oscilloscopes, waveform generators, liquid nitrogen, lasers, and what-have-you are an important part of the process. There is nothing wrong with entertainment. If the "teaching" is going badly in the sense that you are losing the class, entertain for a while. On one occasion, I was talking about electric charge and I needed to create a diversion, so we suddenly switched to a review of temperature and I poured liquid nitrogen all over the teacher's desk. In so doing, attention was returned (and, in fact, I became a hero). Then, talking about the temperature of the molecules, we got to the components of molecules and eventually back to charge, which was supposedly the topic of the day. So, if you want them to sit, make sure you are playing with liquid nitrogen, lasers, or oscilloscopes.

Far better, however, is to have the children involved. This is easy for most subjects; my most successful topics are temperature, states of matter, rotation, and vibration. To demonstrate the latter, I had the students stand still, holding hands, very close together-as a solid. They vibrated and rotated. They were heated up (by a real blow torch, of course), then they let go, but mingled slowly as a liquid (holding hands to the count of three). I heated them some more and they roamed around bouncing off each other and the walls as a gas. (I lost control at this point and couldn't regain it. The teacher saved me.) While in the gaseous state, we developed the meaning of temperature and pressure (with only minimal damage to the walls of the classroom). The concepts of momentum and kinetic energy, the equipartition theorem, and several other basic, seemingly unrelated matters emerged in a perfectly natural manner. The coulomb law, magnets, electric current, and a host of electromagnetic phenomena can be investigated by students physically moving around the room, acting out the role of coils, magnets, wires and what-have-you.

The third rule is reinforcement and repetition. You must commit yourself for several sessions, say at least four or five for any given class. Seven sessions, one every two weeks, proved very effective for me. Every time you return, fold in a review of what you did last time. Some of us are finally getting this message for teaching college-level physics. Use posters a lot. Never just talk. At the very least, walk around the room with a poster in your hands. Leave the posters in the room for the students to stare at between trips.

Finally, this has to be fun for you or it's not worth it and it won't work. Each session for me was about one hour of thinking, one hour of poster making, one hour of gathering bits and pieces in the physics department and putting them in the trunk of my car, one hour of driving, and one hour at the school. So, not counting the thousands of hours of preparation, it's a weekend morning thinking and postermaking and a weekday morning or afternoon of actual teaching. As with any activity, the more teaching you do, the more effecient you become at it. For example, I have a very large suitcase with tennis balls, magnets, a ring stand, all my posters, coaxial cables and connectors, various tools, string and sealing wax (literally), and other odds and ends that I keep permanently. The college will never miss them.

I have a writeup that gives my plan for each of seven sessions or so, followed by my own critique and Marlene Davis' critique of the session. I also have a (rejected) NSF pre-proposal proposal that outlines what could be done in a highly effective manner with three or four teachers. This material is available to anyone who wishes it. This year, I am going to do presentations at the grade-five level for the first time, and I am told they will no longer be willing to 

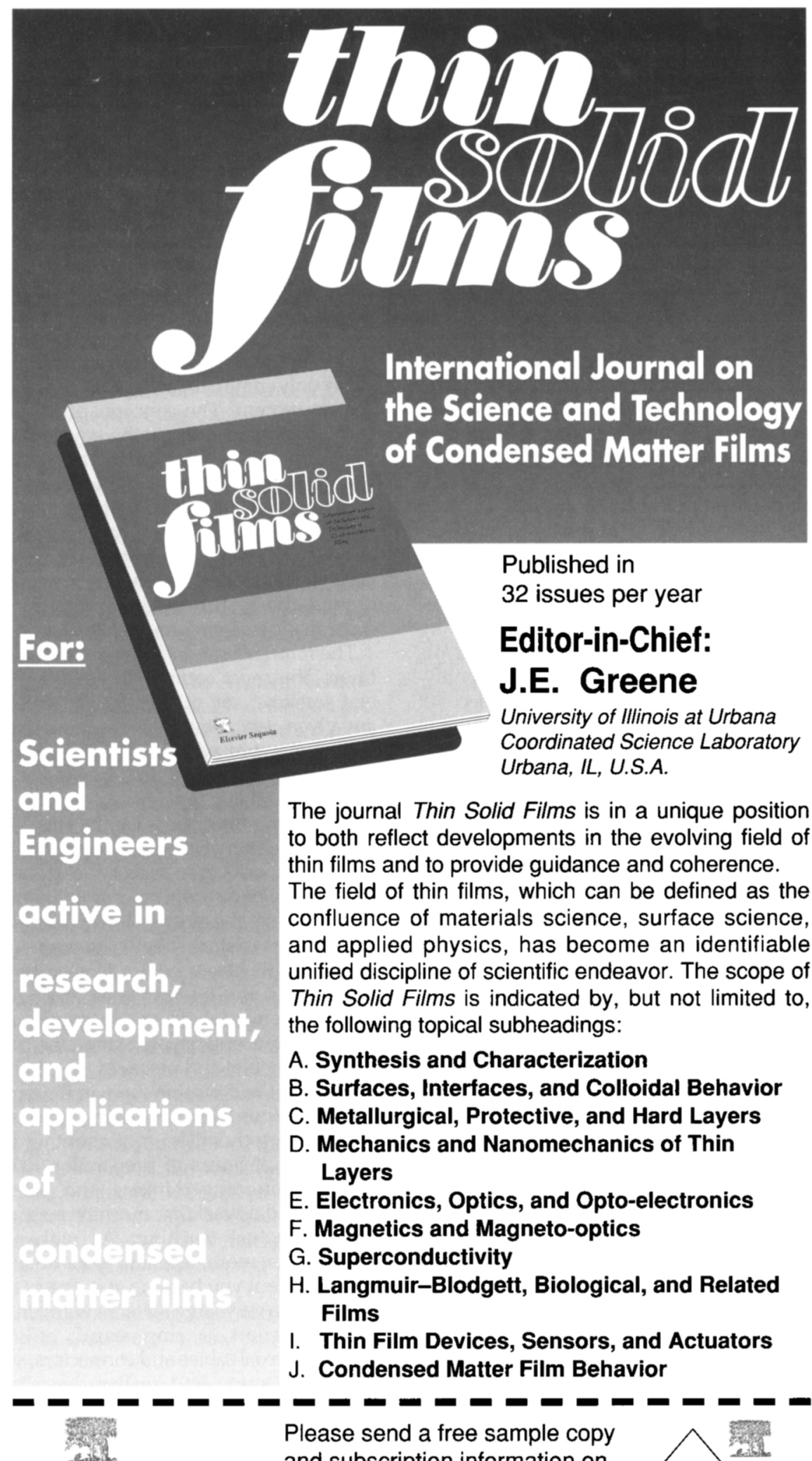

\section{ELSEVIER \\ SEQUOIA}

P.O. Box 564

$\mathrm{CH}-1001$ Lausanne 1, Switzerland

Tel.: +41 (21) 207381

Fax: $+41(21) 235444$

For customers in the U.S.A. and Canada:

Elsevier Science

Publishing Co., Inc.

Attn.: Journal Information Center

655 Avenue of the Americas

New York, NY 10010, U.S.A

Tel.: +1 (212) $633-3750$

Fax: +1 (212) 633-3764
Please send a free sample copy and subscription information on THIN SOLID FILMS

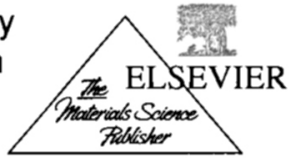

Name:

Company/Institute: ลั

Street:

City:

Country:

Postal Code:

Date:

\section{EDUCATION EXCHANGE}

take part in some of my games. Isn't that a shame? We acquire our social hang-ups so early. So now I have to think up a new strategy.

\section{PETER BECKMANN}

Peter Beckmann is a professor in the Department of Physics, Bryn Mawr College, Bryn Mawr, PA 19010.

The Education Exchange highlights the experiences of scientists and engineers with local schools, along with helpful hints and resources. If you would like to share your own involvement in science education, contact Finley Shapiro, Department of Electrical and Computer Engineering, Drexel University, Philadelphia, PA 19104 U.S.A.; telephone (215) 895-6749; Fax (215) 895-1695; Email: shapiro@ece.drexel.edu

To receive additional information on how you can get involved in enhancing K-12 science education, circle number 120 on the Reader Service Card.

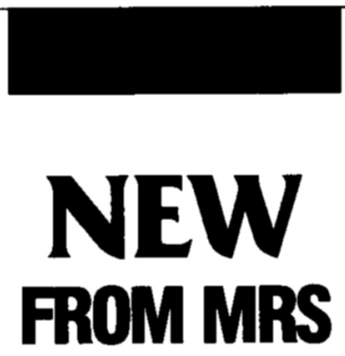

\section{Ferroelectric Thin Films II}

(1991 MRS Fall Meeting, Boston, MA) Editors: A. Kingon, E. Myers, B. Tuttle

ISBN: $1-55899-137-9$

Code: 243 - B

\$48 MRS Members

$\$ 59$ U.S. List

$\$ 70$ Foreign

Order from:

Materials Research Society

9800 McKnight Road

Pittsburgh, PA 15237

(412) $367-3012$

FAX (412) 367-4373. 